\title{
Light-weight Design of Tower Crane Boom Structure Based on Multi-objective Optimization
}

\author{
Jie JIA ${ }^{a}$, Yipin WAN ${ }^{b}$ \\ The Key Laboratory of Road Construction Technology and Equipment, Chang'an University, Xi'an \\ 710064, China \\ aemail: chdjj1818@163.com, bemail:438733130@qq.com
}

\section{Keywords: Crane Boom; Finite Element; Light-weight Design; Multi-objective Optimization}

\begin{abstract}
A finite element model of QTZ5010 tower arm is established by using ANSYS parameter design language (APDL), through static simulation, the stress and strain distribution and its strength and stiffness margin is obtained. With the cross sectional dimensions as the design variables and stress and strain of boom under extreme working conditions as restrain conditions, the mathematical optimization model is established. The fuzzy algorithm and genetic algorithm are used to calculate iteratively for minimal mass. Analysis results show that boom mass reduces by $309 \mathrm{~kg}$ and realizes its structural light-weighting design. Compares with the original structure, the optimized structure strength no significant drop, still meet the requirements of the specification and design of tower crane.
\end{abstract}

\section{Introduction}

The core issue of the realization of energy conservation and emissions reduction for tower crane is to reduce its structural mass, crane boom is the key component of tower crane, its lightweight design is vital for the whole machine structure lightweight. The lightweight design of crane boom is that the structure weight is decreased at the same time meet the lifting performance [1]. Lightweight design is achieved by using light-duty material and optimizing the structure [2]. Hai-bin ZHENG investigated a type crane boom structure size optimization by the finite element method [3]. Yun-xia HONG established optimization mathematical model of crane boom by adopting DOE experimental deign theory to realize the structure size optimization [4]. Yang yang and da-tong chen put forward the optimization strategy about lifting-point position and shape steel size of crane boom, program optimizer and realize the structure optimization [5]. Using advanced optimization theory to improve the existing products and achieve the purpose of cost savings, by this way can enterprises focus on core competencies in order to adapt to the needs of the social development. Based on lightweight design of tower crane produced by Jing Long engineering machinery company, with the aim to optimize the structure size and mass, structural strength as constraint. The structural optimization mathematical model is set up, using multi-objective optimization algorithm [6] to calculate iteratively for lightweight, and the optimization results are analyzed and verified.

\section{Finite element analysis of crane boom}

The connections point of boom root and tower body are treated as nodes to establish finite element model of QTZ5010 type tower crane 50m boom structure with the aid of APDL. Beam188 elements and free meshing are used, which can simplify the modeling, decrease the total nodes and increase the analysis speed. The element number is 388947 , the node number is 148682 . Crane beam structure finite element model (FEM) drawing of partial enlargement is shown in figure 1. Maximum working range of crane boom is $50 \mathrm{~m}$, minimum working range is $2 \mathrm{~m}$, considering the wind load, force diagram of the working process is shown in figure 2. 


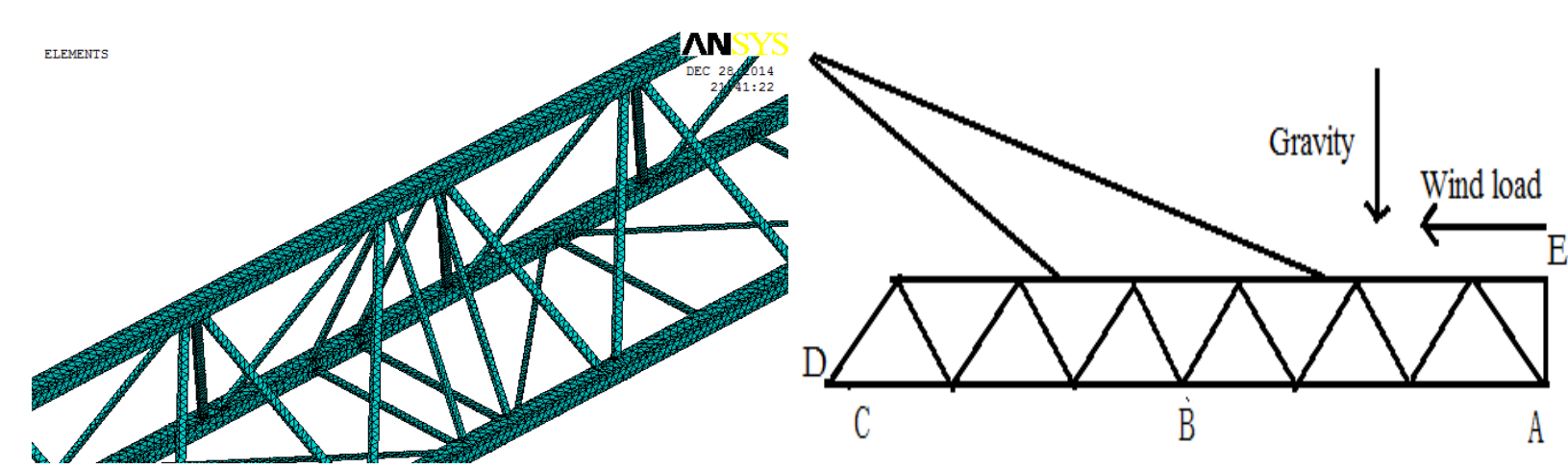

Figure 1 Crane boom FEM of partial enlargement Figure 2 Force distributing diagrammatic sketch

In the ultra static experiments, the 1.25 times of rated lifting load is adopted [7], loading position is respectively A, B, C. Point A is the end $50 \mathrm{~m}$ of boom, point $\mathrm{B}$ is middle position $26 \mathrm{~m}$, point $\mathrm{C}$ is $2 \mathrm{~m}$ position, the load in typical working condition [8] and displacement constraints as shown in table 1.

Table 1 Crane boom load and displacement constraints

\begin{tabular}{|c|c|c|c|}
\hline Working condition & One & Two & Three \\
\hline Lifted load/N & 12250 & 28836.5 & 61250 \\
\hline Loading position & $\mathrm{A}$ & $\mathrm{B}$ & $\mathrm{C}$ \\
\hline Wind load/N & 343 & 343 & 343 \\
\hline Loading position & \multicolumn{2}{|c|}{ The section nodes of the end of boom } \\
\hline $\begin{array}{c}\text { displacement } \\
\text { constraints }\end{array}$ & $\begin{array}{c}\text { Lower chord D end all constraints, upper chord connection point distance } \\
\text { from D 12.5 m and 35 m vertical displacement constraints }\end{array}$ \\
\hline
\end{tabular}

In accordance with load and loading method in table 1, statics analysis results and danger point location of crane boom are obtained under three conditions. With the addition of wind load, stress nephogram results of statics analysis under three conditions as shown in figure 3.

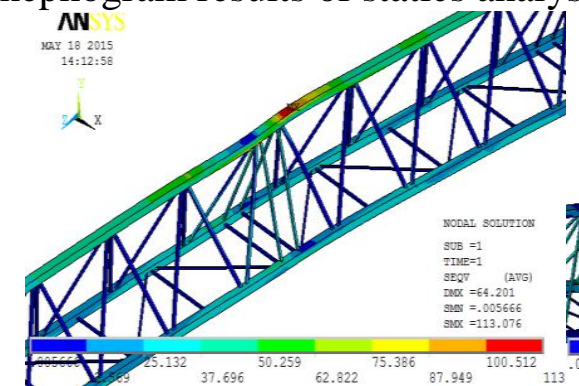

(a)Condition a

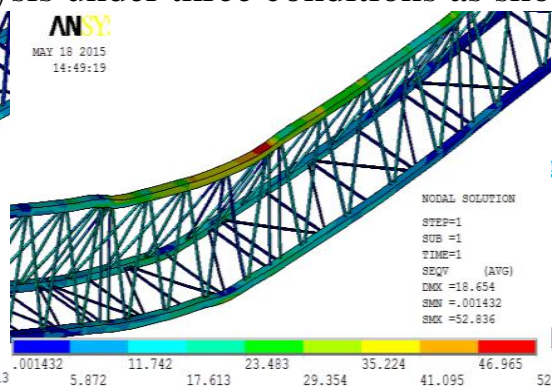

(b) Condition b

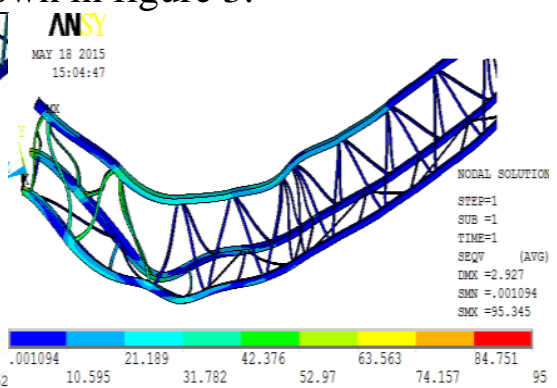

(c) Condition c

Figure 3 Stress nephogram of statics analysis in typical working condition

Statics analysis results in the three kinds of working condition are shown in table 2.

Table 2 Summary table of statics analysis

\begin{tabular}{|c|c|c|c|}
\hline Working condition & One & Two & Three \\
\hline Maximum stress/MPa & 113.08 & 52.84 & 117.43 \\
\hline Maximum displacement/mm & 64.20 & 18.65 & 2.93 \\
\hline
\end{tabular}

The result shows that the maximum stress is $117.43 \mathrm{MPa}$, less than the material allowable stress $175 \mathrm{MPa}$. The maximum displacement deformation is $64.21 \mathrm{~mm}$, per meter deformation is 1.28 $\mathrm{mm} / \mathrm{m}$, less than the national standard $1.5 \mathrm{~mm} / \mathrm{m}$. QTZ5010 type tower crane boom structure can be designed for lightweight design, so as to reduce the weight and save the expense.

\section{Modeling of multi-objective optimization and solving}

Boom multi-objective optimization is to realize that multiple parameters specified in optimization model are synchronous optimal [9]. Multi-objective optimization design process aim for structure size and mass crane boom of crane boom is shown in figure 4. 


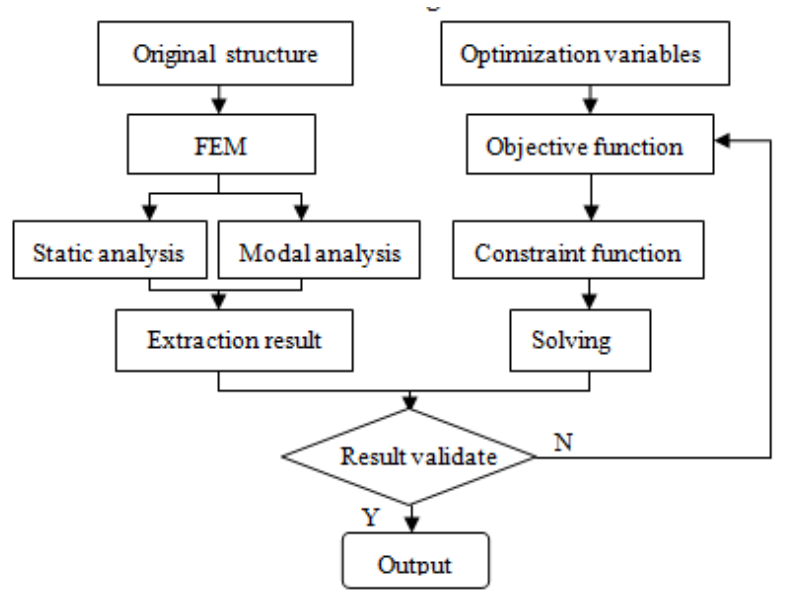

Figure 4 multi-objective optimization design flow chart

According to the structural characteristics of crane boom [10] to determine the design variables as shown in table 3, variable interval is determined based on original structure size.

Table 3 Multi-objective optimization design variables

\begin{tabular}{|c|c|l|c|}
\hline Boom structure & DV & Boom structure & DV \\
\hline Diagonal web bore & R1 & Chord thickness a & T1 \\
\hline Diagonal web OD & R2 & Chord thickness b & T2 \\
\hline Vertical web bore & E1 & Chord thickness c & T3 \\
\hline Vertical web OD & E2 & Chord thickness d & T4 \\
\hline
\end{tabular}

According to the structural finite element analysis results, the multi-objective optimization function as shown in formula (1):

$$
f(x)=\min \rho V\left(x_{i}\right)
$$

Constraint includes performance constraints and boundary constraints, structure lightweight design result should meet the structural stiffness. To establish two state variables: the stress variable $S$ and displacement variable D. The corresponding stress constraints as shown in formula (2):

$$
S_{\max }=\max \left(S_{i}\right) \leq[S]
$$

The corresponding displacement constraints as shown in formula (3):

$$
D_{\text {max }}=\max \left(D_{i}\right) \leq[D]
$$

In the above formula, $\mathrm{f}(\mathrm{x})$ is the structure mass; $\rho$ is material density; $V\left(x_{i}\right)$ is the structure volume; $x i$ is design variable. The $S_{\max }$ is the maximum equivalent stress, $\mathrm{Si}$ is equivalent stress of the number i node, $[S]$ is the material allowable stress. $\mathrm{D}_{\max }$ is maximum displacement deformation; Di is Displacement deformation of the number i node, [D] is allowable displacement deformation.

The crane boom structure is optimized in Design Opt of ANSYS. The change of design variables in the optimization process is shown in figure 5 and figure 6.

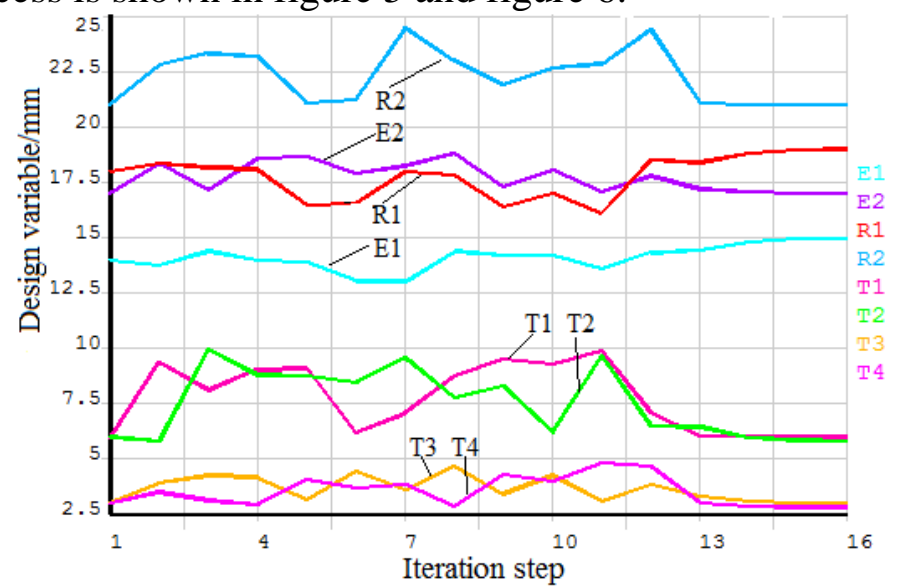

Figure 5 Optimization process graph of design variables 


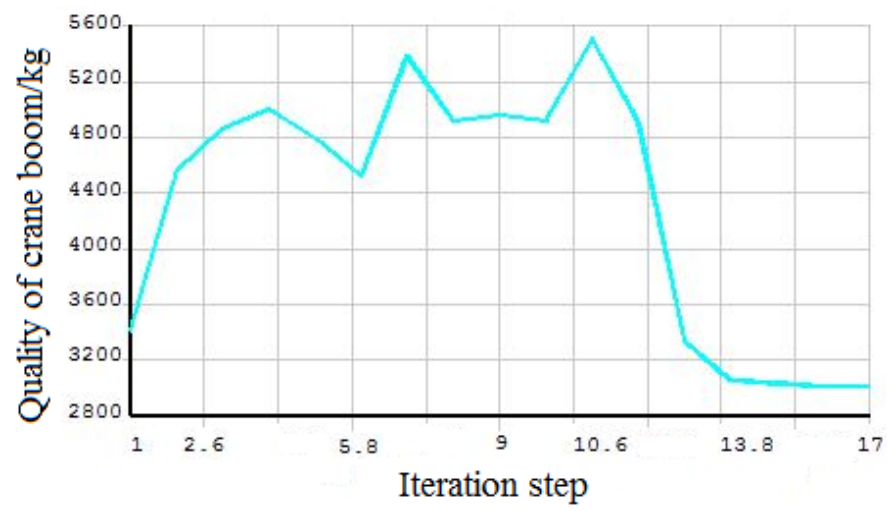

Figure 6 Optimization process graph of objective function values

The analysis results are sorted out, actual value and Variation of before and after optimization design variables as shown in table 4.

Table 4 Change table of relevant variables before and after optimization

\begin{tabular}{|c|c|c|c|c|c|c|c|c|c|}
\hline $\begin{array}{c}\text { Design } \\
\text { variables }\end{array}$ & Before & After & $\begin{array}{c}\text { Round } \\
\text { value }\end{array}$ & $\begin{array}{c}\text { Change } \\
\text { ratio }\end{array}$ & $\begin{array}{c}\text { Design } \\
\text { variables }\end{array}$ & Before & After & $\begin{array}{c}\text { Round } \\
\text { value }\end{array}$ & $\begin{array}{c}\text { Change } \\
\text { ratio }\end{array}$ \\
\hline $\mathrm{R} 1 / \mathrm{mm}$ & 18 & 18.97 & 19 & $+5.5 \%$ & $\mathrm{~T} 3 / \mathrm{mm}$ & 3 & 3.023 & 3 & $0 \%$ \\
\hline $\mathrm{R} 2 / \mathrm{mm}$ & 21 & 21.01 & 21 & $0 \%$ & $\mathrm{~T} 4 / \mathrm{mm}$ & 3 & 2.82 & 2.8 & $6.1 \%$ \\
\hline $\mathrm{E} 1 / \mathrm{mm}$ & 14 & 14.94 & 15 & $+6.8 \%$ & $\mathrm{~W} / \mathrm{kg}$ & 2663 & 2353 & 2354 & $11.6 \%$ \\
\hline $\mathrm{E} 2 / \mathrm{mm}$ & 17 & 17.01 & 17 & $0 \%$ & $\mathrm{~S} / \mathrm{MPa}$ & 117.43 & 120.8 & 120.85 & $+4.7 \%$ \\
\hline $\mathrm{T} 1 / \mathrm{mm}$ & 6 & 6.01 & 6 & $0 \%$ & $\mathrm{D} / \mathrm{mm}$ & 64.20 & 70.32 & 70.32 & $+9.5 \%$ \\
\hline $\mathrm{T} 2 / \mathrm{mm}$ & 6 & 5.84 & 5.8 & $-2.9 \%$ & -- & -- & -- & -- & -- \\
\hline
\end{tabular}

Through the optimization of crane boom structure size, the following conclusion can be drew: (1) the mass of the crane boom reduces $309 \mathrm{~kg}$, equivalent to $11.6 \%$ weight loss than before, which saves raw material; (2) after the optimization, considering the $\mathrm{X}$ factor in practical engineering, its size need to retain a certain margin, so the optimization results are rounded.

\section{Verification of optimized model}

According to the optimized structure, the size of original model is modified and load constraint is applied as table 1 . The stress result of statics analysis as shown in figure 7.

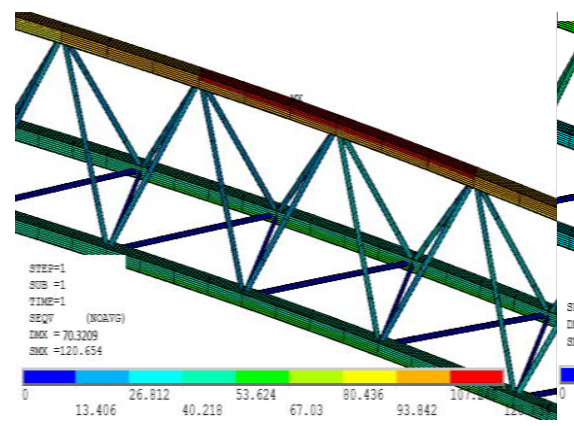

(a)Condition a

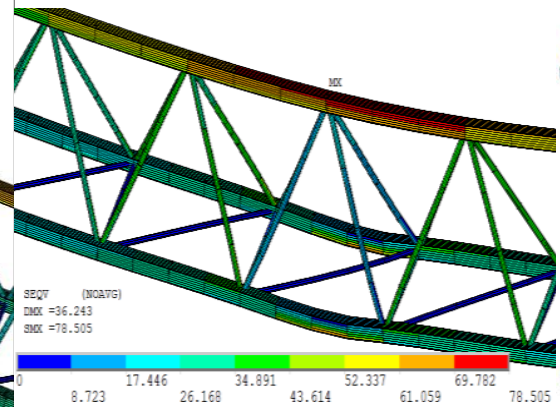

(b) Condition b

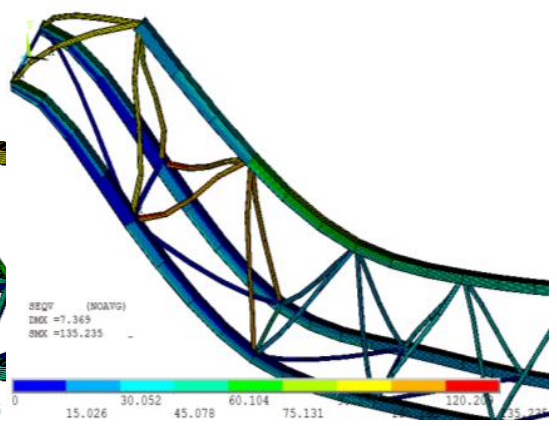

(c) Condition c

Figure 7 Stress nephogram of statics analysis in typical working condition after optimization The comparison of analysis results before and after optimization is made, as shown in table 5.

Table 5 Summary table of statics analysis

\begin{tabular}{|c|c|c|c|c|}
\hline $\begin{array}{c}\text { Typical working } \\
\text { conditions }\end{array}$ & $\begin{array}{c}\text { Equivalent stress } \\
\text { before } \\
\text { optimization /MPa }\end{array}$ & $\begin{array}{c}\text { Equivalent stress } \\
\text { after optimization } \\
\text { /MPa }\end{array}$ & $\begin{array}{c}\text { Displacement } \\
\text { before optimization } \\
\text { /mm }\end{array}$ & $\begin{array}{c}\text { Displacement after } \\
\text { optimization /mm }\end{array}$ \\
\hline Condition a & 113.08 & 120.07 & 64.20 & 70.32 \\
\hline Condition b & 52.84 & 78.51 & 18.65 & 36.24 \\
\hline Condition c & 117.43 & 135.24 & 2.93 & 7.37 \\
\hline
\end{tabular}


Optimized statics analysis results show that the maximum stress is $135.24 \mathrm{MPa}$, which increases $17.81 \mathrm{MPa}$ than former, still less than the material allowable stress $175 \mathrm{MPa}$; The maximum displacement deformation increased by $6.12 \mathrm{~mm}$, is still in the safe range.

Modal analysis is a kind of analysis technology to determine the structure vibration characteristics, the natural frequency and modal parameters can be obtained through it. Without considering the damping $\mathrm{C}$ and external load $\mathrm{Q}$, theoretical formula for structural modal analysis of tower crane [11].

According to the loading ways of the constraint in table 1, respectively calculates before and after optimization finite element model for model analysis, first 6 modals extracted as shown in table 6.

Table 6 Summary table of constraint modal analysis results

\begin{tabular}{|c|c|c|c|c|c|c|c|}
\hline Natural frequency & Before & After & Change ratio & $\begin{array}{c}\text { Natural } \\
\text { frequency }\end{array}$ & Before & After Change ratio \\
\hline First-order $/ \mathrm{Hz}$ & 1.08 & 1.18 & $+9.26 \%$ & Fourth-order $/ \mathrm{Hz}$ & 2.24 & 2.21 & $-9.43 \%$ \\
\hline Second-order $/ \mathrm{Hz}$ & 1.16 & 1.20 & $+3.45 \%$ & Fifth-order $/ \mathrm{Hz}$ & 2.85 & 2.41 & $-15.44 \%$ \\
\hline Third-order $/ \mathrm{Hz}$ & 1.79 & 1.63 & $-8.94 \%$ & Sixth-order $/ \mathrm{Hz}$ & 3.17 & 2.58 & $-18.61 \%$ \\
\hline
\end{tabular}

The modal analysis results shows that the first two order natural frequency increases of optimized structure, three to six order natural frequency decreases and the structure rigidity is slightly improved.

The finite element analysis and modal analysis about optimized crane boom showed that optimized size of QTZ5010 type tower crane boom structure is safe, the material performance is effectively used and the weight of complete machine is reduced. The minimum stress increases after optimization, but the growth rate is not large, the maximum stress is less than the allowable stress of material, in a safe range, The optimized structure of tower crane realizes the lightweight design and cost saving.

\section{Conclusion}

Through multi-objective optimization analysis of the QTZ5010 type crane boom, the following conclusion is obtained. The finite element analysis model of crane boom structure is established. Through static analysis it is sure that its strength is too abundant and the lightweight design can be done to reduce weight. To improve the performances of tower cranes, a mathematical model of multipurpose optimization is established to optimize the strength and stiffness, the mass of the crane boom reduces $309 \mathrm{~kg}$, equivalent to $11.6 \%$ weight loss than before. The finite element analysis data and modal analysis data of crane boom of before and after optimization showed that: Maximum stress of optimized structure increases slightly, less than the material allowable stress; Rigidity of optimized structure increases slightly. Optimization results indicate that the combination of finite element analysis technology to establish a multi-objective optimization mathematical model is feasible, it provides a feasible reference for lightweight design of old tower crane structure.

\section{Acknowledgement}

In this paper, the research was sponsored by the National Key Technology Research and Development Program of the Ministry of Science and Technology of China (Project No. 2015BAF07B02).

\section{References}

[1] Xie Ran, Lan Fengchong, Chen Jiqing, etc.: Multi-objective Optimization Method in Car-body Structure Light-weight Design with Reliability Requirement. Journal of Mechanical Engineering, 2011, 47(4): $117-124$.

[2] Wang Ping, Zheng Songlin, Wu Guangqiang. Multidisciplinary Design Optimization of Vehicle Body 
Structure Based on Collaborative Optimization and Multi-objective Genetic Algorithm. Journal of Mechanical Engineering ,2011,47(2): 102-108.

[3] Zheng haibin, Peng Weiping, Zhang Dake. Optimal analysis of jib for tower crane. Construction Machinery, 2005(8): 87-89.

[4] Hou Yunxia. The application of the DOE technology in boom optimal design. Ship Science and Technology, 2015,37(2): 180-183.

[5] Yang Yang, Qin Datong, Yang Tao. A Study on Design Optimization for Dual Lifting-point Boom of Tower Crane. Construction Machinery and Equipment, 2003(6): 16-19.

[6] Jia Jinxin, Li Quantong, GaoXingwei, etc. Design of engine inlet based mufti objective optimization algorithm. Journal of Machine Design, 2011, 28 (4): 75-79.

[7] PRC National Standard. GB/T 13752 - 92 china standard book number.Beijing: Standards Press of China, 1993.

[8] WANG Dong-ming, YIN Yu-feng, WANG Dan, ZHANG Yang, etc. Dynamic analysis of tower crane structure and load calculation method. Journal of Machine Design, 2014, 31 (7):85-88.

[9] ARNAUD Z, CAROLINE G, MARC G. Pareto memetic algorithm for multiple objective optimization with an industrial application.Journal of Heuristics, 2008, 14 (4):313-333.

[10] ROSHANIAN J, KESHAVARZ Z. Effect of variable selection on multidisciplinary design optimization: A flight vehicle example. Chinese Journal of Aeronautics, 2007 (20): 86-96.

[11] CUI Shao-jie, FAN Shun-cheng GUAN Xiao-tian, etc. Analysis of dynamic characteristics and influence on luffing jib of tower crane. Journal of Machine Design, 2015,32 (2): 66-69. 